\title{
The Impact of a Competitive Learning Strategy on Developing EFL Students' Translation Skills at the Faculty of Specific Education
}

\author{
Dr. Nadia Lotfy Abdel El-Hallim
}

Lecturer of Curriculum \& EFL Instruct

Faculty of Specific Education

Zagazig University

Dr. Mona Salah Abdalla

Lecturer of Curriculum \& EFL Instruction

Faculty of Specific Education

Zagazig University

\section{Abstract:}

The study was an attempt to investigate the impact of
competitive learning on developing translation skills
of the first year EFL students at the faculty of Specific Education. The sample of the study consisted of 80 students divided into two groups: An experimental group of 40 students and the control one of 40 students. The groups were randomly chosen from the EFL students at the Faculty of Specific Education. A Competitive learning strategy was used in teaching the experimental group, while the regular method was used in teaching the control one in the first term of the academic year 2017-2018. The study instruments were (a) a translation skills questionnaire which was divided into four parts of translation skills with their sub-ones underneath sub-skills including: reading comprehension, production, researching and analytical skills, (b) a translation test that was designed and validated to be used as a pre-posttest. Having administered the test, data were collected and analyzed. The results of the study revealed that the competitive learning strategy had a positive influence on translation skills.

Keywords: Competitive Learning, Translation Skills, EFL

\section{Introduction}

In recent years, many attempts have been made to improve the methods and techniques that enable language learners to achieve their goal which is communicating accurately and appropriately in a foreign language. According to theories of socialization, schools perform two main purposes: (a) filling 
social roles, and (b) fostering the development of individual personalities. Those functions are accomplished directly by the academic curriculum that fosters cognitive or occupational skills and indirectly through the implicit curriculum which trains pupils to think and behave in accordance with social norms. Among the non-academic outcomes of the implicit curriculum are students' orientation toward competing and cooperating with others (Shwalb, Shwalb \& Nakazawa, 1995), a strong influence on the way pupils interact with each other, their attitudes to school and their academic achievement, as well as their self-concepts (Rzoska \& Ward, 1991). In addition, research has suggested the cooperative, competitive and individualistic teaching methods may produce different educational outcomes and that their overall effectiveness may vary depending on students' ethnic and cultural backgrounds (Ahlgren, 1983). Accordingly, learning is mainly associated with the classroom and is often competitive, but to Tabesh (2007), competitive learning is often motivated by a competition and is basically an extra-curricular activity which develops creativity and problem solving skills.

\section{1.a. Definition of Competitive Learning}

Competitive learning have different definitions that are closely related to teaching/learning situations or in light of what takes place in its context. Therefore, competitive situations according to Johnson \& Johnson (1989 ), are ones in which students work against each other to achieve a goal that only one or a few can attain. In competition, students perceive that they can obtain their goals if and only if other students in the class fail to obtain their goals.

To Coakley (1994: 78 ), competition has been defined as the "social process that occurs when rewards are given to people on the basis of how their performances compare with the performances of others doing the same task or participating in the same event". And to Tabesh (2007), competitive learning is a type of learning motivated by participation in a competition. Competitive learning could be between individuals or groups. 
Competitive learning is usually on extra-curricular activity which can cause improvement of the educational system. It may also be seen as a contest in which two or more people are engaged where typically only one or a few participants will win and others will not (Webster, 2008).

From another lens, competitive learning may have negative sides in which one student wins and the other(s) lose (Akinbobola,2009; Roger and Johnson, 1994). As a result, the competitive goal invites the learners to compete against each other leaving the participants with a win-lose situation (Lin, 1997).

\section{1.b. Kinds of Competitive Learning}

Competition is used for the purpose of evaluating the position of people in various tasks. Dettmer (2005) stated that if the purpose is selecting the one who carries out the task more efficiently, then it can really prove to be useful since it is needed in everyday life. Generally, there are two kinds of competitive goal structure that can be seen: (1) constructive, and (2) destructive. The desired form of competitiveness, which is called constructive, is the one in which the winner tries to assist the loser by giving him/her some tips as to how they could achieve the break through stage. Quite the contrary in the destructive from of competitiveness, the winner does not help the loser in no way at all (Deutsch , Coleman \& Marcus , 2006 ). From another perspective, Griffiths \& Podirsky (2002) see that the competitive learning can be interpersonal (between individuals), or intergroup (between groups), where a group setting is appropriate. This strategy has been described as the most appropriate when students need to review learned material.

\section{1. c. Factors affecting competition in the classroom}

According to Monsas \& Eblehard (1990), the frequency and intensity of a student's competition in a class depends on numerous factors that are intertwined in a complex way. A student's competitive attitude in the class is influenced by his/her intellectual abilities, parental and family socio economic 
and educational background, competitive norms in the family socio economic and educational background, competitive norms in the family, certain personality characteristics, gender, etc. Therefore, a school class can be very colorful in terms of the students' competitive characteristics (highly competitive or extremely non-competitive) comprising it.

In addition, Walters (2002) sheds light on some other factors such as (a) the willingness to compete, (b) equal opportunities for winning, (c) competing against oneself more than each other, and (d) rewarding the competitors.

\section{1. d. Importance of competitive learning}

Competition is evident throughout all societies, all lives, and all recorded histories. It transcends time and place, as well as all manner of people in all aspects of life including business, sport and education that constitute fundamental competitive environments (Eitzen \& Sage , 2003; Fulop, 2002). Furthermore , competitive processes have been implicated in multiple linguistic phenomena, including speech segmentation (Norris, Mc Queen \& Cutler, 1995), visual , and spoken - word processing (Gaskell , 2003; Rodd , Gaskell \& Marslen-Wilson, 2004) and grammatical parsing (Vosse \& Kempen ,2000) . They also found throughout the cognitive system in vision (Masland, 2001), selective attention (Beck \& Kastner, 2005 ), action selection (Cisek, 2007), and decision making (Spivey, Dale, Knoblich \& Grosjean, 2010 ).

Hence, competition has been suggested as a means of enhancing the motivational appeal of educational activities, and as a way to foster learner involvement and excitement in the activity (Butler and Kedar , 1990; Clinkenbeard , 1989 ; Davis and Rimm , 1985). Adding an element of competition between individuals or groups is widely believed to be a motivational - 
enrichment strategy in play, work and education. Despite the fact that competition is encouraged as an appropriate goal structure in the form of various academic contests to motivate people to perform to the best of their ability (Yu et al., 2002)

To put it clear, researchers have observed the socialization of competitiveness in the schools of various cultures. In Germany, for instance, competitive examinations for entrance to secondary school motivate students from a very early age, and determine individuals' future social and economic status. In contrast, Israeil schools have a strong tradition of education which values cooperativeness, reflecting the original collectivist and humanistic values of Israeli society. In the United States, The ideology of competiveness has long been entrenched in the implicit school curriculum (Shwalb, and Nakazawa, 1995)

In (2008), Chan \& Lam compared the effects of competitive and non-competitive classrooms on students' writing selfefficacy when they engaged in vicarious learning. The participants were 71 grade 7 students in Hong Kong, using prior writing performance for stratified random sampling; and students were assigned either to a competitive or a noncompetitive classroom. Students learned how to compose similes and metaphors in Chinese. In the competitive classroom, students' self-efficacy decreased when they engaged in vicarious learning. In the non-competitive classroom, students' selfefficacy did not show a significant change when they engaged in vicarious learning. The findings suggested that when students engaged in vicarious learning in a competitive classroom, their self-efficacy might be threatened. Implications for efforts to design constructive context for vicarious learning are discussed.

Hosseini (2012) compared Competitive Team-Based Learning (CTBL), with Structured Academic Controversy (SAC) the most popular method of Cooperative Learning (CL) - on language proficiency of Iranian EFL college students. This goal, the intention to compare the effects of the selected teaching methods on the dependent variable of the study, was addressed with respect to different-level achievers (i.e., low, average, and 
high achievers) of the target group in the field study, in Iran. Out of a total population of 68, forty EFL senior college students at Bojnord Azad University, in Iran, were selected to serve the study, after conducting a test of English language proficiency. The subjects were randomly put into control and experimental groups. While the control group was taught through SAC, the experimental group experienced learning the English language through CTBL. The results are explored further in the article and the author discusses the probable causes for the results of the study, sheds light on the pedagogical implications, and suggests recommendations for further research

Briefly, Shindler (2009) summarized the benefits of competition. Following are some :

1. Promoting a shift from means/process to ends/products

2. Promoting a tendency to take on a mentality defined by "fear of failure" (winning would consequently relieve the anxious condition) and a helpless pattern.

3. Shifting the emphasis from quality relationships to effective relationships.

4. Accentuating the effects of existing social hierarchy and ability levels.

5. Increasing the level of anxiety for a performance (pressure may potentially refine skill given a more demanding performance context.

\section{1.e. Positive versus negative competitions in the classroom}

Some educators and psychologists see competition as a cornerstone in the development of self -reliance and as a powerful motive in stimulating effort and productivity. Others see competition as a source of hostility, self-doubt and anxiety which in turn decrease learning outcome (El-koumy,1994). Besides, Lam et al. (2004) found that competition had a positive impact on performance goals and learning motivation in the classroom. Dettmer (2004) posited that "learning by losing" was a valuable process for students preparing for professions where 
working under pressure was necessary. Also, competition is a powerful motivator for student behavior regularly applied in education research. Some studies have found competition to have positive effects on student learning (Chenge, et al .,2009; Han \& Chan , 2008; Ke, 2008a ; 2008b; Yu \& Liu , 2009).

Holding the same perspective, Good and Brophy (2008) believe that competitive learning (a) generate interest and excitement in topics or tasks that would otherwise be of limited interest to students, (b) may be appropriate if all students have a chance to win, and when a team approach is used rather than individually based evaluations, (c) may be appropriate within the context of behavior management, such as when the teacher is attempting to reduce disruptive behaviors and increase positive behaviors; and (d) will prepare students for competition in their lives beyond school.

Sometimes, competition is labeled 'healthy' when it has specific feature: when (a) the primary goal is fun, (b) the competitive goal is not "valuable/real" nor is it characterized that way, (c) the competition has a short duration and is characterized by high energy, (d) there is no long - term effect from the episode, (e) all individuals or groups see a reasonable chance of winning, and (f) the students all firmly understand these points. These practices may reduce the likelihood that the same students are always the winners and losers, in which the losers become embarrassed and demoralized. Further, competition between groups (using a team-based approach) may increase cooperation within groups, as students are unified in working towards a common goal,

Although competitive learning has advantages, it has its own demerits too (e.g., Good and Brophy, (2008); Mussweiler,2003; Stapesl \& Koomen,2005). Competition may negatively impact students' development, learning , and motivation . For example, if students become preoccupied with winning or losing the competitive activity, they may lose sight of important instructional objectives and content. From the students' perspective, performance takes precedence over 
learning. This is because competition involves social comparisons, where students are exposed to conflicting sets of comparative information and processes, including failures in the competition. In particular most competitions are zero-sum activities, in which one student loses the competition while the other wins. If The loser attributes this failure to lack of ability, he/she might feel frustrated or helpless (Dweck ,2000) .

Hence, Yu et al., (2002) Shindler (2007) and, Shindler (2009) demonstrated that there are few principles to consider when judging whether a competitive classroom situation is more beneficial or less. First: Competition for valuable outcomes will have more detrimental effects on a class than competition for trivial and/or symbolic out comes. There are essentially three types of "valuable or real" outcomes. They are: (a) material things of value. This includes privileges that have a substantive impact, b) the teacher's conspicuous and/or lasting affection, and (c) recorded grades.

Second: The shorter the life of the competition, the more likely it is to have a beneficial effect. The length of the contest increases its sense of prominence and decreases its sense of intensity and fun- both undesirable effects.

Third: The leader of the competition must place a conspicuous emphasis on process over product. If winning is the point, students will take on a "Just do what it takes" attitude. If students are encouraged to value the process, they will feel justified in staying focused on the learning out come and feel assured that it is okay to put their attention into quality as the primary goal.

\section{Translation}

Translation is the conversion of written text from one language into another so that the new, translated text reflects the content of the original text and corresponding cultural perceptions and customs of the target audience. Translation makes communication possible among people who read or write different languages and have different cultural heritages. 
Translation is not the process of finding an equivalent word in the target language for each word in the original document. That is because there may be no equivalent words, or there may be more than one equivalent word and the translator must examine the context to choose the one that is best. Additionally, the ways in which words are combined to create meaning vary from language to language, and translating words in the order they appear in the original text often will not make sense in another language.

Translation can be viewed, according to Chabban 1984, as a science, an art and a skill. It is a science in the sense that it necessitates knowledge of the structure and make-up of the two languages concerned. It is an art since it entails artfulness in reconstructing the product into something presentable to the reader who is not supposed to know the original. It is a skill because it entails the ability to smooth over any difficulty in the expression of the translation, and the ability to give a translation of something that has no equal in the language of the translation.

As translation is regarded a communicative activity, it involves communication between the teacher and the student. Learners are encouraged "to discuss rights and wrongs as well as problems related to the translation task" (Leonardi, 2009, p.145). On the one hand, students are involved in a conversation on the translation topic, which helps them strengthen their speaking skills. On the other hand, students are requested to talk to both the teacher and other learners, and through listening to both the lecturer and the students improve their listening skills.

\section{2.a. Significance of translation}

Translation is necessary to communicate information to those who need it, want it, or are entitled to it but do not understand the language of the original document. Translation plays an increasingly important role in and for society. It enables people to correspond ideas and culture regardless of the different tongues involved. Chabban (1984:5) views translation as "a finicky job"; since it has not yet been reduced to strict scientific rules, and it allows for the differences that are known 
to exist between different personalities. Translation is a heavily subjective art especially when it deals with matters outside the realm of science, which differs from that of art where almost everything requires a different meaning.

According to Leonardi (2011), translation as a pedagogical instrument can be successfully employed at any level of proficiency, at school or university, as a valuable and creative teaching aid to support, integrate and further strengthen the four traditional language skills: reading, writing, speaking and listening. One of the possible ways to integrate translation in foreign language classes can be through the use of translation activities.

Translation is sometimes referred to as the fifth language skill alongside the other four basic skills of listening, speaking, reading, writing: 'Translation holds a special importance at an intermediate and advanced level: in the advanced or final stage of language teaching, translation from L1 to L2 and L2 to L1 is recognized as the fifth skill and the most important social skill since it promotes communication and understanding between strangers (Ross 2000, 62).

Translation might provide a guided practice in reading. Before starting translating a text it "should be read carefully and analyzed in detail to determine the contents in terms of what, how and why it is said" (Leonardi, 2009,p.143). Careful text analysis improves students' reading comprehension and promotes vocabulary development. Translation can help students improve their writing skills because it is a transfer of a text from one language into another. Leonardi (2010) claims that a good translation should flow naturally, re-create both the style and the context of the original text, and follow target language conventions.

And so, the benefits of translation activities include practice of all language skills, i.e. reading, writing, speaking and listening. In terms of communicative competence, accuracy, clarity and 
flexibility can be developed. Translation is a real-life, natural activity which many learners use on a daily basis either formally or informally. Translation is a common strategy used by many learners even if teachers do not encourage it. Discussion of differences and similarities between languages help students understand problems caused by their native language. Developing skills in translation is a natural and logical part of improving language proficiency(http://www.teachingenglish.org.uk/think/articles/transl ation-activities-language-classroom, 2009).

The translation process, in a broader sense, is a series of translating activities involving three phases: pre-translation, translation, and post translation, according to Gouadec (2007: 12-3). Pre-translation includes anything that takes place up to the moment the translator actually receives the material for translation, and post-translation covers all activities that follow the delivery of the translated material.

\section{2.c. Translation problems}

During the translation process, translators may encounter many problems (phonological problems, lexical problems, grammatical problems, and stylistic problems). According to Ghazala (1995), these problems are due to either sound and lexis (word) or grammar and style (1995) cited in AYADI (2010)

To El Zeini (1994), translation problems can be divided also into linguistic problems and cultural problems: the linguistic include grammatical differences, lexical ambiguity and meaning ambiguity, whereas the cultural ones refer to different situational features, different tone, mode or tenor of is course (Baker 1996). These problems can also be categorized into six main areas of difficulty in the process of translating from Arabic into English and vice versa. These are: lexis, morphology, syntax, textual differences, rhetorical differences, and pragmatic factors (El Zeini 1994). 
Another level of linguistic difficulty in the work of translation is what As-sayyd (1995) found when she conducted a study to compare and assess some problems in translating the fair names of Allah in the Holy Qur'an. She pointed out that one of the major problems of translation is over-translation (when the translation gives more information than what is contained in the original), under-translation (when the translation gives less information than what is contained in the original), and untranslatability (when the translation fails to represent the information contained in the original).

There are three types of barriers between an initial state and a goal state which constitute a problem. The first of them is a synthesis problem which concerns the means for the unknown transformation.

However, according to Nord (1991), there are four categories of translation problems: (a) pragmatic translation problems which arise from the particular situation and represent a specific contrast of SL vs. TL recipients, SL vs. TL medium, SL vs. TL function etc. Those problems can be identified by the extra textual factors of the text-analytical model, (b) cultural translation problems are a result of the differences in culture e.g. specific habits, expectations, norms and conventions concerning verbal and other behaviour, (c) linguistic translation problems which are connected with the structural differences between languages in lexis, sentence structure and supra-segmental features e.g. 'false friends.', (d) text-specific translation problems are those which may appear in a particular text and cannot be classified as pragmatic, cultural or linguistic ones.

Culture, constitutes another major problem that faces translators. A bad model of translated pieces of literature may give misconceptions about the original. That is why Fionty (2001) thought that badly translated texts distort the original of its tone and cultural references, while Zidan (1994) wondered about the possible role of target culture content as a motivating variable in enhancing or hindering the attainment of linguistic, communicative and, more importantly, cultural objectives of EFL 
education. Hassan (1997) emphasized this notion when he pointed out the importance of paying attention to the translation of irony in the source language context. He clarified that this will not only transfer the features of the language translated but also its cultural characteristics. Abdellah (2003) explained that the context can entirely change the meaning of a linguistic expression and accordingly its translation if the translator did not pay attention to the parallel linguistic, cultural and emotional contexts.

The problem of most current translation teaching practices in Egyptian universities, besides being a marginalized subject, is that translation teachers start their classes where translation processes end. Most teachers would ask the students to translate a given passage at home and then discuss the selected translations and criticize them linguistically, and the teacher would finally choose what $\mathrm{s} / \mathrm{he}$ believes to be the most appropriate translation without referring to any theoretical frame work or without even convincing students of his/ her choice.

Shaheen (nd) comments on the state of translation teaching in Arab universities saying (nd: 83): "translation teachers more often do not devote much time to lexical features, reducing the translation class to a mere dictation of drills of words and clichés. Text-books are mere collections of texts selected from different sources, i.e. newspapers, journals, books, etc. They are sometimes prefaced by practical tips and pieces of advice to students and prospective translators on how to translate. Translation classes are reduced to the mere contrasting of grammatical structures and lexis in two language systems. The unit of translating is the word or the sentence. This has a damaging effect on the students who may think that translating is a word-for-word operation, where words and grammatical structures can be substituted by others in a foreign language".

\section{2.d. Translation requirements}

Translation also requires some skills such as language acquisition, text competence, research competence, cultural 
competence, transfer competence and abilities such as decisionmaking, creativity, to give quick responses especially in the simultaneous translation and to arrange the time of response well. Translation actually consists of a set of activities and skills, but the fact that the person wanting to participate in a translation training program is inclined to translation will also accelerate the process of acquiring the skills that will be introduced in other sections. For example, translation has moved to different areas especially due to the impact of the developments in communication technology and current conditions. Therefore it requires the ability of quickly choosing among many alternatives and making decisions. What is important for translators is not to know everything, but to know how and where to find that information when needed, and choose the most appropriate one (Pym: 2012, 9- 10). That requires 'the orientation reaction' ability of the translator. This kind of ability is one of perceptual motor skills and refers to the ability of quickly choosing one from so many options. Likewise, especially interpreters must be able to respond quickly in a short time during the translation task.

As explained before, translation consists of many different sub-skills. In the case of missing one of these skills, deficiencies will occur in the translation process. However, learning of the translation and acquiring skills will be much more efficient and functional thanks to the motivation of the students, their predisposition towards translation, their interest in translation, conducted studies and exercises. In addition to the weak and strong capabilities of the students, text analysis in the previously acquired first language, text comprehension, understanding, and the amount of experiences gained in written and oral expression skills and a variety of other personal characteristics also take an active role in applying translation skills in an effective way. Students who are not open to social events before attending to an undergraduate program, already accustomed to the system of multiple choice questions undeveloped writing and speaking skills, will not have acquired an adequate experience in the skills required for translation and will exhibit a lower ability, also will 
give the false impression to instructors that $\mathrm{s} /$ he does not have necessary translation capabilities.

Upon looking at the translation activity, it is observed that there are different opinions on this issue. According to some, translation necessitates having ability or a disposition. For example, in order to make literary translations, one should have a predisposition towards literature or be able to write as well as the author himself. This kind of a suggestion is caused by the characteristic of literary translation itself. According to Gile (2009:9), literary translators must be able to understand both the basic informational meaning of texts, and fine shades of meaning as expressed by subtle choices of words and expressions, as well as by their rhythm, music, and images- and be highly aware of cultural facts, norms, trends and atmospheres. However, according to Eruz, translation is a task that can be handled by the translation competence. And translation competence is acquired through education. In addition, any translation task requires an intense mental effort (Eruz, 2008: 211). Translation competence can also be learned and taught and it includes cultural competence, language acquisition, text competence, expert knowledge, knowledge about translation, translation-oriented information in a professional field and research methods (Eruz, 2008: 219).

Before translating, a number of crucial factors ought to be taken into account. The language level of the students, their educational and cultural background, and interests. To Harmer (2001), it is necessary to consider the four main elements of a plan: (a) Activities (what students will be doing in the classroom, the way they will be grouped, what kind of activity each of them will solve), (b) Skills (what language skill the students will develop), (c) Language (what elements of a language will be practiced), (d) Content (lesson planners have to select content which has a good chance of provoking interest and involvement).

\section{2.e. Translation Phases:}

Translation with which my study is concerned is the one in the middle of the two phases, and which in turn is divided into 
three stages: 1.Pre-transfer, 2. Transfer, and 3. Post-transfer. Each stage corresponds to what Jakobsen (2002) calls: 1. Predrafting (start-up), 2. Drafting (writing phase), and 3. Postdrafting (revision phase), respectively. The first stage refers to all operations prior to the actual translating', including preparation of the material, pre-reading of the text, terminology searches to obtain key words in the source text, etc. The second, 'transfer' or 'drafting', is the core activity of translation, shifting to another language-culture combination. The third, revision phase, is related to editing and corrections that are to be made to meet the client's quality requirements.

\section{2.f. Related Studies on Translation skills}

Carreres's (2006) conducted a questionnaire among 31 second and third year students of modern languages at the University of Cambridge. All respondents agreed that translation should be taught in a modern language degree, and most of them believed that translation into the FL was a very useful language learning device, especially when learning vocabulary. Half of the students also considered that translation was among the most effective methods to learn a language, though not all of them found translation activities enjoyable or gratifying.

Liao's study (2006) explored the role of translation in Taiwanese EFL learners in terms of their learning beliefs about using translation and their main learning strategies. Students showed a medium to high level use of translation as a learning strategy. They also reported that translation played a positive role in their English learning experiences, but more proficient learners tended to report negative beliefs about translation and less use of translation, as compared with less proficient learners.

Kavaliauskienë and Kaminskienë (2007) also carried out a survey of students' perceptions of the amount of mother tongue they needed and mental translation they used in learning English for Specific Purposes (ESP). Their main findings suggested that all learners seemed to rely on their mother tongue in learning ESP, and that the amount of native language needed had a lot to do with their proficiency level and linguistic situations. 
Rolin-Ianziti and Varshney (2008)analyzed the functions that beginner learners of French in an Australian university attributed to their native language and found that it was preferred to perform classroom management and that it had a positive affective role, since it may alleviate classroom anxiety, though they also found that translation was a de-motivating factor for learners. Brooks-Lewis' survey (2009), on its turn, reports learners' positive attitudes towards the use of their native language in the FL classroom in Mexico. After the completion of an EFL course, participants wrote their perceptions and showed positive response to the inclusion of the L1 because it had been beneficial to their foreign language learning experience.

Ashouri and Fotovatnia (2010 )analyzed Iranian EFL learners' beliefs about translation and whether risk taking and tolerance of ambiguity had any effect on learners' beliefs about translation. They concluded that only risk-taking affected learners' beliefs and those learners taking risks had negative belief about translation.

Madkour (2016)investigated the effect of integrating project-based teaching methodology into teaching machine translation on students' performance. Data was collected from the graduate students in the College of Languages and Translation, at Imam Muhammad Ibn Saud Islamic University, Riyadh, Saudi Arabia. Quantitative data instruments included a Likert scale questionnaire, students' exam results, and students' assignments. Qualitative data was gathered using two groups, of 20 students each, from the same research population to explore the effectiveness of project-based teaching methodology. The first group of participants was taught for one semester using traditional teaching methods that depended on direct instruction and memorization of information while the second group of participants was involved in creative projects about various topics on machine translation. Content analysis was conducted to evaluate the participants' projects. A comparison of the two groups' final exam results and assignments was made to provide 
statistical evidence regarding the impact of project-based teaching approach on students' performance. The discussions of this research include topics on theories and systems of machine translation, the concepts of localization and hybridization, project-based teaching methodologies, and educational technology. The recommendations emphasize the importance of adopting brain-based strategies such as project-based techniques in teaching machine translation, providing professional development programs on using cognitive teaching approaches, and equipping translation laboratories with most recent technologies. The significance of this research derives from being a contribution in three specific areas: integrating education research into teaching machine translation to motivate students to improve their performance; employing educational technology to bridge the gap between theories and practice of machine translation; providing an implementation of creative teaching in machine translation through presenting students' creative projects. The integrative teaching model, which the researcher presented in this research, is a new approach for solving students' problems in machine translation.

\section{Problem of the study}

To come to a closer identification of the problem, the researchers conducted a pilot study based on EFL first year students at the Faculty of Specific Education, Zagazig University $(n=20)$; it was carried out during the first semester in the academic year 2017/2018. A questionnaire was designed in order to gather information about the priorities of translation skills required for first year students. The results of the translation skills test revealed that the percentage of the students' responses to these skills was less than $50 \%$. Table (1) shows the percentage of the students' responses to each translation skills.

Table 1. Results of the pilot translation skills test

\begin{tabular}{|c|c|}
\hline Translation skills & Percentages \\
\hline Reading Comprehension Skills & $\mathbf{3 0 \%}$ \\
\hline Production Skills & $\mathbf{2 5 \%}$ \\
\hline Researching Skills & $\mathbf{2 3 \%}$ \\
\hline Analytical Skills & $\mathbf{2 2 \%}$ \\
\hline
\end{tabular}


Based upon the pilot study results, it could be claimed that the first year EFL students at the Faculty of Specific Education lacked translation skills, and the current study was seen to develop them through the use of competitive learning strategy. Therefore, The study could be crystalized in the following main question:

What is the impact of a competitive learning strategy on developing EFL students' translation skills at the Faculty of Specific Education?

The following sub-questions were, then, derived:

a. What are the necessary EFL translation skills required for the first year students' translation skills?

b. To what extent do these students master these skills?

c. How far is using a competitive learning strategy effective in developing EFL students' translation skills at the Faculty of Specific Education?

\section{Hypotheses of the study:}

The research hypotheses have been formulated as follows:

1. There would not be a statistically significant difference between the mean scores of the control group and those of the experimental one on translation skills pretest as a whole and its dimensions.

2. There would be a statistically significant difference between the mean scores of the control group and those of the experimental group on translation skills posttest as a whole and its dimensions, in favor of the experimental group.

3. There would be a statistically significant difference between the mean scores of the experimental group on translation skills pre and posttests as a whole and their dimensions, in favor of the posttest.

4. Competitive learning strategy is effective in developing translation skills among the first year EFL students. 


\section{Method}

To fulfill the objectives of this study, competitive learning strategy was used to determine its impact on developing the first year EFL students at the Faculty of Specific Education, Zagazig University. The participants $(n=80)$ were divided into two groups: the experimental group $(n=40)$, and the control group $(n=40)$. The researchers used developed a translation skills questionnaire in order to determine the most important translation skills suitable for the participants concerned. It consisted of four major skills (Reading comprehension skills, researching skills, analytical skills and production skills) and each skill consisted of some sub-skills. Three degrees of importance on each item were: very important, important, and unimportant. Having approved the questionnaire, an EFL translation skills test was developed of four parts. It was validated by a specialist jury, and then piloted. The test was preadministered to make sure that the students of the experimental and the control groups were at the same level before the experimentation. A competitive-learning strategy was developed and used in teaching translation to the experimental group while the control group received the regular way of teaching. The strategy was provided in twelve sessions. Each session took 90 minutes, and the activities used in each session were varied and different aiming at developing the participants' translation skills. The strategy proposed took 10 weeks, then the post-test was administered at the end of the semester.

\section{Results}

In order to test the hypotheses of the study, data collected from pre and post testing were treated statistically using means, standard deviations, t-values and effect sizes. The results obtained are shown below. 
Table 2. Means, Standard Deviations and t-values of the mean scores of the control group and those of the experimental one on translation skills pretest

\begin{tabular}{|c|c|c|c|c|c|c|c|}
\hline $\begin{array}{c}\text { Translation } \\
\text { Skills }\end{array}$ & Groups & $\mathbf{N}$ & M & SD & df & $\mathbf{t}$ & Sig. \\
\hline \multirow{2}{*}{$\begin{array}{l}\text { RDCOMP } \\
\text { Skills Pre }\end{array}$} & Control & 40 & 6.60 & 1.98 & \multirow{2}{*}{78} & \multirow{2}{*}{-1.18} & \multirow{2}{*}{$\begin{array}{c}0.241 \\
\text { Not sig. }\end{array}$} \\
\hline & Exp. & 40 & 7.15 & 2.17 & & & \\
\hline \multirow{2}{*}{$\begin{array}{c}\text { PRDCT Skills } \\
\text { Pre } \\
\end{array}$} & Control & 40 & 6.97 & 2.25 & \multirow{2}{*}{78} & \multirow{2}{*}{-0.36} & 0.717 \\
\hline & Exp. & 40 & 7.15 & 2.032 & & & Not sig. \\
\hline \multirow{2}{*}{ Total Pretest } & Control & 40 & 13.57 & 3.24 & \multirow{2}{*}{78} & \multirow{2}{*}{-1.06} & 0.293 \\
\hline & Exp. & 40 & 14.30 & 2.87 & & & Not sig. \\
\hline \multirow{2}{*}{$\begin{array}{c}\text { RSRCH Skills } \\
\text { Pre }\end{array}$} & Control & 40 & 7.125 & 2.10 & \multirow{2}{*}{78} & \multirow{2}{*}{-0.66} & 0.513 \\
\hline & Exp. & 40 & 7.45 & 2.31 & & & Not sig. \\
\hline \multirow{2}{*}{$\begin{array}{c}\text { ANLTC Skills } \\
\text { Pre }\end{array}$} & Control & 40 & 7.27 & 1.81 & \multirow{2}{*}{78} & \multirow{2}{*}{-0.59} & 0.560 \\
\hline & Exp. & 40 & 7.52 & 1.99 & & & Not sig. \\
\hline \multirow{2}{*}{ Total Pretest } & Control & 40 & 14.40 & 2.43 & \multirow{2}{*}{78} & \multirow{2}{*}{-0.87} & 0.389 \\
\hline & Exp. & 40 & 14.97 & 3.41 & & & Not sig. \\
\hline
\end{tabular}

Note: RDCOMP = Reading Comprehension, PRDCT = Production, RSRCH $=$ Researching, ANLTC $=$ Analytical

As shown in Table 2, the results of t-test comparing the control group and the experimental one on translation skills pretest show that there is no significant differences between the mean scores of both groups on that test as a whole and its dimensions. This result supports the first hypothesis that states that "There would not be a statistically significant difference between the mean scores of the control group and those of the experimental one on translation skills pretest as a whole and its dimensions". This result is represented graphically in Figure 1.

Figure 1. Comparison of t-values of the mean scores of the control group and those of the experimental one on translation skills pretest

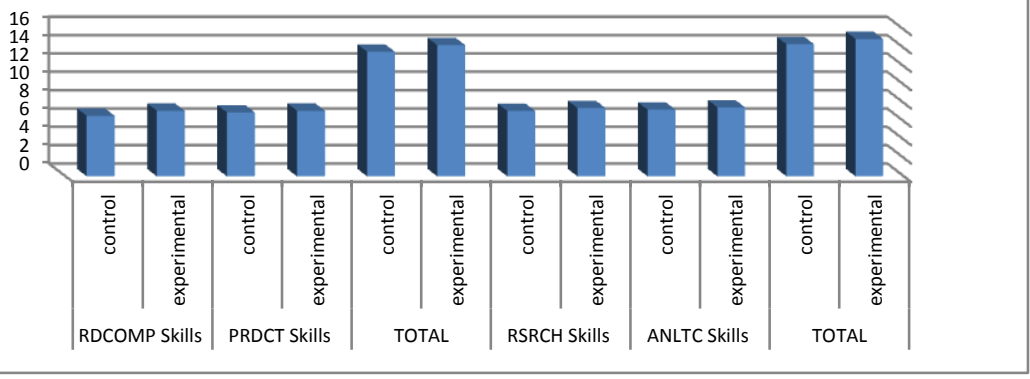


As shown in Table 3, the results of t-test comparing the control group and the experimental one on translation skills posttest show that there is a statistical difference between the mean scores of the two groups in favor of the experimental group. Though the effect sizes of the intervention is moderate in the dimension of the translation skills test, it is high in the test as a whole. With that, this result supports the second hypothesis that states: "There would be a statistically significant difference between the mean scores of the control group and those of the experimental group on translation skills posttest as a whole and its dimensions, in favor of the experimental group". Figure 2 displays the results of Table 3 graphically.

Table 3. Means, Standard Deviations, $t$-values and Effect size of the mean scores of the control group and those of the experimental group on translation skills posttest

\begin{tabular}{|c|c|c|c|c|c|c|c|c|}
\hline $\begin{array}{c}\text { Translation } \\
\text { Skills }\end{array}$ & Group & $\mathbf{N}$ & $\mathbf{M}$ & SD & df & $\mathbf{t}$ & Sig. & ES \\
\hline \multirow{2}{*}{$\begin{array}{l}\text { RDCOMP } \\
\text { Skills Post }\end{array}$} & Control & 40 & 12.02 & 3.754 & \multirow[b]{2}{*}{78} & \multirow[b]{2}{*}{-12.28} & \multirow[b]{2}{*}{$\begin{array}{c}0.000 \\
\text { sig. }\end{array}$} & \multirow{2}{*}{$\begin{array}{l}0.659 \\
\text { mdrte }\end{array}$} \\
\hline & Exp. & 40 & 20.00 & 1.660 & & & & \\
\hline \multirow[b]{2}{*}{$\begin{array}{c}\text { PRDCT } \\
\text { Skills Post }\end{array}$} & Control & 40 & 13.22 & 4.11 & \multirow[b]{2}{*}{78} & \multirow[b]{2}{*}{-9.99} & \multirow[b]{2}{*}{$\begin{array}{c}0.000 \\
\text { sig. }\end{array}$} & \multirow[b]{2}{*}{$\begin{array}{l}0.675 \\
\text { mdrt }\end{array}$} \\
\hline & Exp. & 40 & 20.05 & 1.31 & & & & \\
\hline \multirow{2}{*}{$\begin{array}{c}\text { Total } \\
\text { Posttest }\end{array}$} & Control & 40 & 25.25 & 7.19 & \multirow{2}{*}{78} & \multirow{2}{*}{-12.53} & \multirow{2}{*}{$\begin{array}{c}0.000 \\
\text { sig. }\end{array}$} & \multirow{2}{*}{$\begin{array}{l}0.668 \\
\text { mdrt }\end{array}$} \\
\hline & Exp. & 40 & 40.05 & 1.98 & & & & \\
\hline \multirow{2}{*}{$\begin{array}{c}\text { RSRCH } \\
\text { Skills Post }\end{array}$} & Control & 40 & 15.02 & 3.08 & \multirow[b]{2}{*}{78} & \multirow{2}{*}{-12.05} & \multirow{2}{*}{$\begin{array}{l}0.000 \\
\text { sig. }\end{array}$} & \multirow{2}{*}{$\begin{array}{l}0.651 \\
\text { mdrt }\end{array}$} \\
\hline & Exp. & 40 & 21.55 & 1.51 & & & & \\
\hline \multirow{2}{*}{$\begin{array}{c}\text { ANLTC } \\
\text { Skills Post }\end{array}$} & Control & 40 & 15.52 & 3.08 & \multirow{2}{*}{78} & \multirow{2}{*}{-10.65} & \multirow{2}{*}{$\begin{array}{c}0.000 \\
\text { sig. }\end{array}$} & \multirow{2}{*}{$\begin{array}{l}0.592 \\
\text { mdrt }\end{array}$} \\
\hline & Exp. & 40 & 21.30 & 1.50 & & & & \\
\hline \multirow{2}{*}{$\begin{array}{c}\text { Total } \\
\text { Posttest }\end{array}$} & Control & 40 & 30.55 & 3.92 & \multirow{2}{*}{78} & \multirow{2}{*}{-17.36} & \multirow{2}{*}{$\begin{array}{c}0.000 \\
\text { sig. }\end{array}$} & \multirow{2}{*}{$\begin{array}{c}0.794 \\
\text { high }\end{array}$} \\
\hline & Exp. & 40 & 42.85 & 2.18 & & & & \\
\hline
\end{tabular}

Note: RDCOMP = Reading Comprehension, PRDCT = Production, $\mathrm{RSRCH}=$ Researching, ANLTC $=$ Analytical, $\mathrm{mdrt}=$ moderate 
Figure 2. Comparison of t-values of the mean scores of the control group and those of the experimental group on translation skills posttest

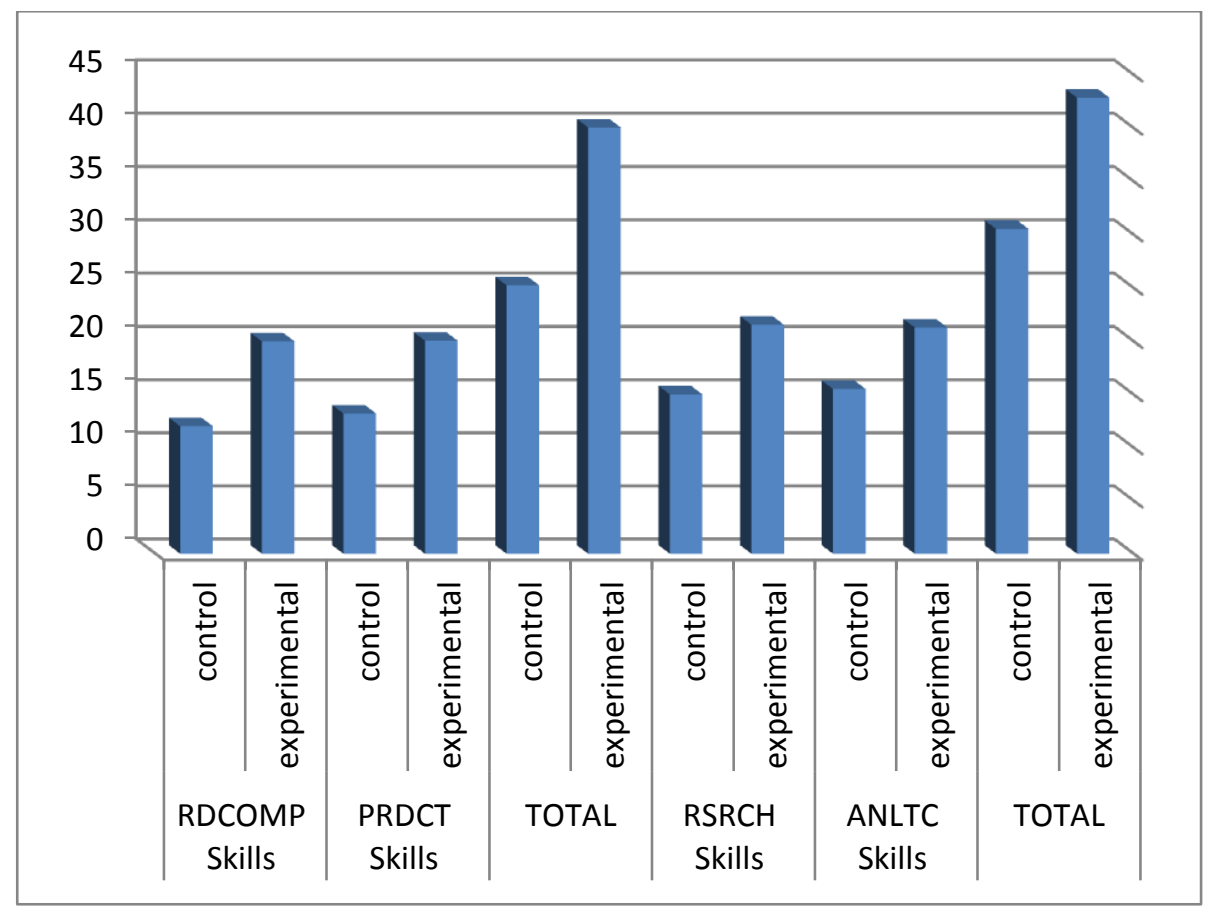

As indicated in Table 4, the results of t-test reveal that there is a statistical difference between the mean scores of the control group and those of the experimental group on translation skills pre and posttests in favor of the posttest. This result supports the third hypothesis that states: "There would be a statistically significant difference between the mean scores of the experimental group on translation skills pre and posttests as a whole and their dimensions, in favor of the posttest". It is also observed that the effect sizes of the intervention revealed concerning the translation skills test as a whole as well as its dimensions - are high. Figure 3 represents the results graphically. 
Table 4. Means, Standard Deviations, $t$-values, and Effect size of the mean scores of the experimental group on translation skills pre and posttests

\begin{tabular}{|c|c|c|c|c|c|c|c|c|}
\hline \begin{tabular}{|c|} 
Translation \\
Skills
\end{tabular} & Measures & $\mathbf{N}$ & Mean & SD & df & $\mathbf{t}$ & Sig. & ES \\
\hline \multirow{2}{*}{$\begin{array}{l}\text { RDCOMP } \\
\text { Skills }\end{array}$} & Pre & 40 & 7.15 & 2.18 & \multirow[b]{2}{*}{39} & \multirow[b]{2}{*}{-57.07} & \multirow{2}{*}{$\begin{array}{l}0.000 \\
\text { sig. }\end{array}$} & \multirow{2}{*}{$\begin{array}{l}0.988 \\
\text { High }\end{array}$} \\
\hline & Post & 40 & 20 & 1.66 & & & & \\
\hline \multirow[b]{2}{*}{ PRDCT kills } & Pre & 40 & 7.15 & 1.32 & \multirow{2}{*}{39} & \multirow[b]{2}{*}{-69.59} & \multirow{2}{*}{$\begin{array}{c}0.000 \\
\text { sig. }\end{array}$} & \multirow{2}{*}{$\begin{array}{l}0.992 \\
\text { High }\end{array}$} \\
\hline & Post & 40 & 20.05 & 2.88 & & & & \\
\hline \multirow[b]{2}{*}{ Total } & Pre & 40 & 14.30 & 1.98 & \multirow[b]{2}{*}{39} & \multirow[b]{2}{*}{-82.63} & \multirow{2}{*}{$\begin{array}{l}0.000 \\
\text { sig. }\end{array}$} & \multirow{2}{*}{$\begin{array}{l}0.994 \\
\text { High }\end{array}$} \\
\hline & Post & 40 & 40 & 2.32 & & & & \\
\hline \multirow{2}{*}{$\begin{array}{l}\text { RSRCH } \\
\text { Skills }\end{array}$} & Pre & 40 & 7.45 & 1352 & \multirow[b]{2}{*}{39} & \multirow[b]{2}{*}{-69.83} & \multirow{2}{*}{$\begin{array}{c}0.000 \\
\text { sig. }\end{array}$} & \multirow{2}{*}{$\begin{array}{c}0.992 \\
\text { High }\end{array}$} \\
\hline & Post & 40 & 21.55 & 1.99 & & & & \\
\hline \multirow{2}{*}{$\begin{array}{l}\text { ANLTC } \\
\text { Skills }\end{array}$} & Pre & 40 & 7.52 & 1.51 & \multirow{2}{*}{39} & \multirow[b]{2}{*}{-79.38} & \multirow{2}{*}{$\begin{array}{l}0.000 \\
\text { sig. }\end{array}$} & \multirow{2}{*}{$\begin{array}{c}0.993 \\
\text { High }\end{array}$} \\
\hline & Post & 40 & 21.30 & 3.42 & & & & \\
\hline \multirow{2}{*}{ Total } & Pre & 40 & 14.97 & 3.42 & \multirow{2}{*}{39} & \multirow{2}{*}{-86.40} & \multirow{2}{*}{$\begin{array}{l}0.000 \\
\text { sig. }\end{array}$} & \multirow{2}{*}{$\begin{array}{c}0.994 \\
\text { High }\end{array}$} \\
\hline & Post & 40 & 42.85 & 2.18 & & & & \\
\hline
\end{tabular}

Figure 3. Comparison of t-values of the mean scores of the experimental group on translation skills pre and posttests

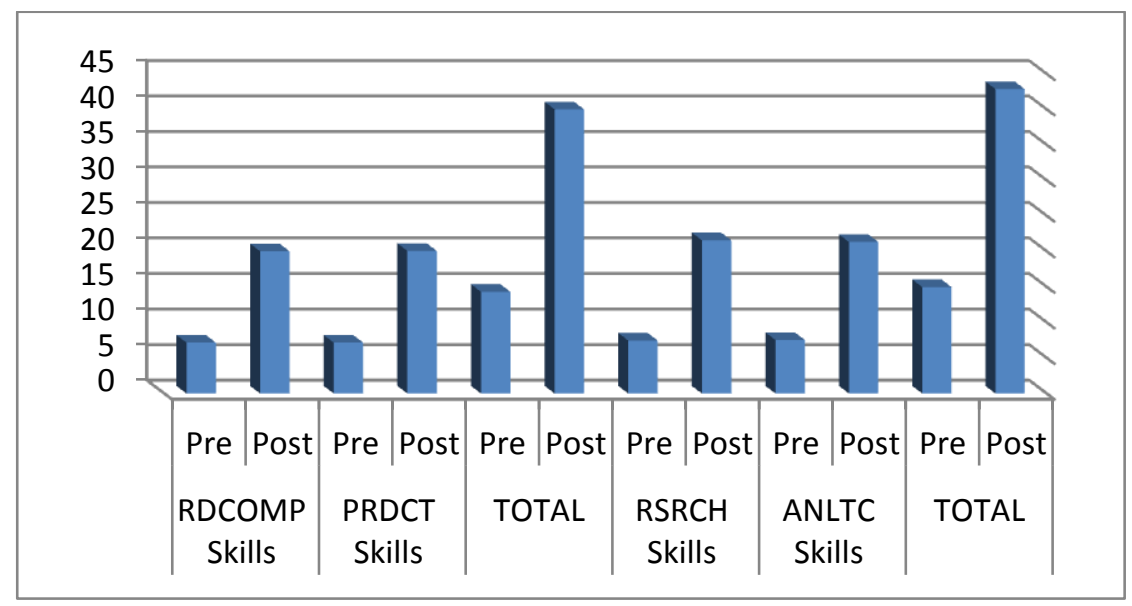




\section{Discussion}

It was hypothesized that using competitive learning would improve the translation skills (comprehension, production, researching and analytical) of English major students in the Faculty of Specific Education. And the results obtained showed that the hypotheses of the study have been verified. The researchers believe that there are more than one explanation standing behind the development happened. One reason for this may be due to a psychological aspect that is the rewards provided to students might have motivated them to perform better. Besides, when applying the competitive learning strategy, they were divided into groups but bearing in mind that even if they were in groups, they would be assessed on the basis of their individual efforts and outcomes. This means that each student was only responsible for his/her own activities and assignments with the encouragement of the instructor(s) to do the best competing against each other. Being "the best" required the students to be both quicker and more accurate in comparison with their classmates. Students who performed the activities or tasks successfully were promised to be more estimated. Since they all had the same chance of winning. The motivation imposed by the instructor(s) for competition seems to have its valuable effect in their performance. This view is supported by many researchers (e.g., Butler and Kedar ,1990 ; Chan \& Lam, 2008 Clinkenbeard ,1989; Coronado, 2012; Davis and Rim, 1985; Fluop ,2002; Hosseini, 2012; Shindler, 2009 ; Shwalb \& Nakazawa, 1995; Yu, 2003).

A second possible explanation of the results may be attributed to a cognitive aspect in that translation skills were divided into four basic skills: comprehension, production, researching, and analytical skills. Through comprehension, students were able to (a) read for gist, and main ideas, (b) identify the meaning of new words and expressions using one or 
more of the structural analysis clues: prefixes, suffixes, roots, word order, punctuation, and sentence patterns , (c) identify the meaning of new words and expressions using one or more of the contextual analysis devices: synonymous, antonyms, examples, and (d) identify the style of the writer: literary, scientific, technical, informative, persuasive, and argumentative. Through production, students were able to (a) pinpoint elements useful for discrimination of the content to be expressed from similar contents, (b) pinpoint redundant elements: choice of words (lexicalization) and attention to their cohesion, and (c) choose the appropriate grammatical structure/s including linear order of words, part of speech, sentence complexity, prepositions and other function words. Through researching, students were able to (a) use bilingual dictionaries for looking up meaning of new words, (b) use related encyclopedias and glossary lists for specialized terms, and (c) use the internet for researching purposes. Through analysis, students were able to (a) identify the" best" meaning that fits into the context, (b) identify the structure in the target language that "best" represents the original, and (c) identify transitions between ideas and the "best" cohesive devices in the target language that represent the original.

A further explanation can be due to a procedural aspect in that using competitive learning might have created a sense of external urgency. This view supported the idea of Johnson and Johnson (2006) that states that competition brings a variable into the equation that shifts the participants' attention from the task itself to attention to the cost of their performance in the task. This means that competition generated interest and excitement in tasks. When between groups, cooperation increased as students were unified in working towards a common goal. Besides, it reduced the disruptive behaviors and increased positive behavior because this may help them to be well-prepared for competition in their lives. This explanation goes with the view of Good and Braphy (2008) who illustrated the merits of competitive learning in the classroom and the view of Dettemer (2004) who affirmed that "learning by losing" was a 
valuable process for students preparing for professions where working under pressure was necessary.

\section{Conclusion and recommendations}

Based on the results of the current study, it can be concluded that competitive learning is a successful teaching strategy in EFL teaching and learning process in general and in teaching translation skills in particular. It is, therefore, recommended that while satisfying the attempts to improve and develop appropriate classroom interactions, competitive strategy should be adequately employed in translation courses at the university level. Also, EFL school teachers and learners are recommended to have training in competitive learning strategy in order for teachers to know how to function that strategy in their English classes, and for students to acquire the competition skills as long as their learning process extends.

\section{References}

Abdellah. A. S (2003). Translations of Near Synonyms in the Qur'an: A context based Analysis. MA Dissertation. Department of Linguistics, School of Oriental and African Studies, SOAS. University of London

Ahlgren, A. (1983). Minnesota School Attitude Survey Manual. In Rzosk, K.M. \& Warda,C.(Eds.). The Effects of Cooperative and Competitive Learning Methods on the Mathematics Achievement, Attitudes toward School, Self-Concepts and Friendship Choices of Maori. Pekeha and Samoan Children. New Zealand Journal. of Psychology, 20, 17-24

As-sayyad, S. M. (1995). The problem of English Translation Equivalence of the fair names of Allah in the Glorious Qu'ran: A Contextual Study. MA thesis, Faculty of Education, Ain Shams University.

AKinbobola, A.O. (2009). Enhancing Students' Attitudes towards Nigerian Senior Secondary School Physics through the Use of Cooperative, Competitive, and Individualistic Learning Strategies. Australian Journal of Teacher Education , 34(1), $1-9$. 
Ashouri, F. and Fotovatnia, Z (2010). The Effect of Individual Differences on Learners' Translation Belief in EFL Learning. English Language Teaching 3(4), 228-236.

Amani, A. (2010). Lexical Translation Problems: The Problem of Translating Phrasal Verbs The Case of Third Year LMD Learners of English. A Master Dissertation in Applied Language Studies . Mentouri University: Constantine Faculty of Letters and Languages

Baker,M. (1996). A Course book on Translation. London and New York:Routledge

Beck, D.M., \& Kastner,S. (2005). Stimulus Context Modulates Competition in Human Extra Striate Cortex. Nature Neuroscience 8, 110-116.

Butler , R.,\& kedar, A. (1990) . Effects of Intergroup Competition and School Philosophy on Student Perceptions, Group Processes, and Performance. Journal of Contemporary Educational Psychology, 15 (4), 301-318.

Carreres, Á(2006). Strange Bedfellows: Translation and Language Teaching. The Teaching of Translation into L2 in Modern Languages Degrees: Uses and Limitations, In Sixth Symposium on Translation, Terminology and Interpretation in Cuba and Canada. December2006,La Havana: Canadian Translators, Terminologists and Interpreters Council (online): 1- 21

Chabban, G.(1984) . An Analysis of the techniques of translation based on some literary material translated from English into Arabic. Ph.D. Thesis, Faculty of Al Alsun, Ain Shams University.

Chan, J.C.Y., \& Lam, S. (2008). Effects of Competition on Students' Self-Efficacy in Vicarious Learning. British Journal of Educational Psychology, 7(1), 95-108.

Cheng , H.N.H., Wu,W. M.C ., Liao , C.C.Y., \& Chan , T.W . (2009). Equal Opportunity Tactic: Lessening Negative Effect in Competition Games in Classrooms. Computers and Education, 53 (3), 866-877. 
Cisek,P.(2007). Cortical Mechanisms of Action Selection: The Affordance Competition Hypothesis. Philosophical Transaction of the Royal Society, 362,1585-1599.

Clinkenbeard, P.R (1989). The Motivation to Win: Negative Aspects of Success at Competition. Journal for the Education of the Gifted, 12 (9), 293-305.

Coakley ,J. (1994): Sport in Society :Issues and Controversies (4th ed .) St. Louis: Times Mirror / Mosbey College.

Coronado, S., Sandoval- Bravo, S., Celso-Arellano, P.L., \&TorresMata, A. (2018). Competitive Learning Using a ThreeParameter Logistic Model. European Journal of Contemporary Education, 7(3), 448-457.

Davis, G., \& Rimm , S. (1985) . Education of the Gifted and Talented (365PP). Englewood Cliffs, NJ: prentice - Hall.

Dettmer , J . (2005) .Competition Photography. Learning by Losing. PSA Journal, 36.

Deustch , M., Coleman , P.T., \& Marcus, E .C. (2006). The Handbook of Conflict Resolution: Theory and Practice. San Francisco: Jossey . Bass .

Dweck , C. (2000) . Self-Theories: Their Role in Motivation, Personality, and Development (Essays in Social Psychology). Philadelphia, PA: Psychology Press.

El Zeini. N. (1994). Criteria for the Evaluation of Translation : A Pragma-stylistic approach. PhD. Thesis, Faculty of Arts, Cairo University.

El-Koumy , A.S.A. (1994) . Effects of Cooperative Versus Competitive Learning on EFL Students' Writing . Suez Canal University. http://ssin.6m/abstract=2371866

Etizen , D.S.,\& Sage , G . H. (2003) .Sociology of North American Sport. (7th ed). New York: Mc Grow Hill

Eruz, S. (2008). Akademik Ceviri Egitimi Ceviri Amaclı Metin Cozumlemesi. İstanbul: Multilingual Yayınları. 
Fionty B. (2001). "Translation Course" part two. On-line Book. Available: http://www.logos.it/pls/dictionary/linguistic_re sources.traduzione_en?lang=en 25 April 2001)

Fluop , M . (2002) .Competition in Educational Settings. Paper

Presented in the Faculty of Education. University of Ljubljana , Slovenia , December.

Gaskell, M. (2003). Lexical Competition and the Acquisition of Novel Words. Journal of Cognition, 89,105-132.

Ghazala, H. (1995). Translation as Problems and Solutions (4th ed.).Syria: Dar El Kalem El-Arabi.

Gile D.(2009). Basic Concepts and Models for Interpreter and Translator Training. Revised Edition. Amsterdam/Philadelphia: John Benjamins Publishing Company.

Good , T.L., \& Brophy , J . E . (2008) .Looking in Classrooms (10th ed.). Boston : Pearson Education .

Gouadec, D. (2007). Translation as a profession. Grand Rapids: John Benjamins Co.

Griffiths , J ., \& Podirsky , M . (2002). Types of Learning .Available :// ehlt : Flinders . edu. au / education / Dlit / 2002 / environs / scott / learntype . htm.

Harmer, J. (2001). The Practice of English Language Teaching, Earson Education Limited: Longman .

Hassan. A.H. (1997). 'Verbal Irony in Arabic and English: A Discourse Approach. MA thesis, Faculty of Education, Ain Shams University.

Hosseini, S.M.H. (2012). A Study of the Effects of Competitive Team-Based Learning and Structured Academic Controversy on the Language Proficiency of Iranian EFL College Senior. International Journal of Adult Vocational Education and Technology, 3 (4), 54-69.

Jakobsen, A. (2002). Logging target text production with Translog. In G. Hansen (Ed.), Probing the Process in Translation: Methods and Results. Copenhagen Studies in Language, 24. (pp. 9-20)Samfundslitteratur: Copenhagen. 
Johnson, D.w., \& Johnson, R.T. (1989). Cooperation and Competition: Theory anal Research. Edina, Mn: Interaction Book Company.

Kavaliauskienë, G and Kaminskienë, L (2007). Translation as a learning tool in English for specific purposes. Kalbotyra, 57(3): 132-139.

Lam ,S.,Yim,P., law ,J.,\& Cheung, R. (2004). The Effects of Competition on Achievement Motivation in Chinese Classrooms .British Journal of Educational Psychology, 74 (2), 281-296.

Leonardi, V( 2010). The Role of Pedagogical Translation in Second Language Acquisition - From Theory to Practice [online]. Bern: International Academic Publishes, available at:

http://books.google.lt/books?id=Zd8DcUFt_wsC\&pg=PA15 $\& \mathrm{dq}=$ peter+lang+publishers+leonardi\&hl=lt\&sa=X\&ei=hMt QT8 [Accessed 13/01/2012].

Leonardi, V (2009). Teaching Business English through Translation. Journal of Language \& Translation [online], 10(1), pp. 139-153, available at: http://www.unish.org/unish/DOWN/PDF/5 1 Leonardi $r$ ev and finalD.pdf [Accessed 13/01/2012].

Leonardi, V(2011) . Pedagogical Translation as a Naturally Occurring Cognitive and Linguistic Activity in Foreign Language Learning. AnnaliOnline di Lettere-Ferrara [online], vol. 1-2, p.17-28, available at: http://eprints.unife.it/annali/lettere/2011voll12/leonardi.pdf [Accessed 22/03/2012].

Liao, P (2006). EFL Learners' Beliefs about and Strategy Use of Translation in English Learning. RELC. Regional Language Centre Journal 37(2), 191-215.

Lin,C.C. (1997). Effects of Goal Structures on Chinese Elementary School Students' Goal Orientation, Achievement, Intrinsic 
Motivation, and Beliefs about Success/Failure. Journal of Educational Psychology, 80, 321-331.

Luce,P.A., \& Pisoni , D.B . (1998). Recognizing Spoken Words: The Neighborhood Activation Model. Ear\& Hearing, 19,1-36.

Madkour, M. (2016). The Application of Functional Linguistic Models for Assessing Quality of Translation: A Descriptive Analytical Study. International Journal of English Linguistics, $6(6)$.

Masland, R.H. (2001). The Fundament Plan of the Retina. Nature Neuroscience, 4 , 877 - 886.

Mc Kinstry , C., Dale , R., \& Spivey , M.J. (2008) . Action Dynamics Reveal Parallel Competition in Decision Making. Psychological Science, 19, 22-24.

Monsas, J., \& Engelhard , G . (1999). Home Environment and the Competitiveness of Highly Accomplished Individuals in Four Talent Fields. Journal of Developmental Psychology, 26 (2), 264-268.

Mussweiler , T. (2003) . Comparison Processes in Social Judgment: Mechanisms and Consequences. Psychological Review, 110, 472-489.

Nord, C. (1991). Text analysis in translation: Theory, methodology, and didactic application of a model for translation-oriented text analysis. Amsterdam/New York, NY: Rodopi

Norris ,D., Mc Queen , J . M., \& Cutler, A. (1995). Competition and Segmentation in Spoken-Word Recognition. Journal of Experimental Psychology: Learning, Memory, and Cognition, $21,1209-1228$.

Pym, A. (2012). Translation skill, sets in a machine, translation age, Intercultural Studies Group Universitat Rovirai Virgili, Tarragona, Spain http://usuaris.tinet.cat/apym/online/training/2012_competence_pym.pdf Accessed 15.01.2015. 
Rodd, J.M., Gaskell , M.G., \& Marslen - Wilson , W.D.C (2004) . Modeling the Effects of Semantic Ambiguity in Word Recognition .Cognitive Science, 28, 89-104

Rolin, I and Varshney, R (2008). Students' views regarding the use of the first language: An exploratory study in a tertiary context maximizing target language use.

Ross, N,( 2000). Interference and Intervention: Using Translation in the EFL Classroom. Modern English Teacher, 9(3). pp.6166.

Rzoska, K.M., \& Ward, C. (1991). The Effects of Cooperative and Competitive Learning Methods on the Mathematics Achievement, Attitudes toward School, Self-Concepts and Friendship Choices of Maori. Pekeha and Samoan Children. New Zealand Journal of Psychology,20,17-24.

Shaheen. M (nd)1991. Theories of Translation and their Application to the Teaching of English/Arabic. Amman, Jordan: Dar Al-Thaqafa library.

Shindler , J. (2009) . Examining the Use of Competition in the Classroom From Transformative Classroom Management. Reproduction is Unlawful without Permission. Available:http:web.calstatela.edu/faculty/jshindl/cm/chap ter18 competition-final.htm.

Shindler, J. (2007) .Transformative Classroom Management ,Pearson Allyn \& Bacon press .

Shwalb, D.W., Shwalb, B.J., \& Nakazawa. J. (1995). Competitive and Cooperative Attitudes: A longitudinal Survey of Japanese Adolescents. Journal of Early Adolescence,15 (1),145-168.

Spivey , M.J., Dale , R., Knoblich , G ., Grosjean , M .(2010) . Do Curved Reaching Movements Emerge from Competing Perception? A Reply to Vanderwel, et al., (2009). Journal of Experimental Psychology: Human Perception and Performance, (36), 251-254

Stallman, H. (2012). A Qualitative Evaluation of Perceptions of the role of Competition in the Success and Distress of Law 
Students. Higher Education Research and Development, 31(6), 891-904.

Stapesl , D.A., \& Koomen , W. (2005) .Competition, Cooperation , and the Effects of others on Me. Journal of Personality and Social Psychology, 88, 1029 -1038 .

Tabesh,y. (2007). Competitive Learning, Sut (Sharif University of Technology. Available: http://docplayer.net/35051829competitive-learning-a-model.html.

Vosse , T., \& Kempen , G . (2000) .Syntactic Structure Assembly in Human Parsing: A Computation Model Based on Competitive Inhibition and a Lexical Grammar. Cognition, $75,105-143$

Walters , L.S. (2000) . Social Aspects of Motivation. Classroom Goal Structure . Journal of Personality and Social Psychology ,65, 904-915.

Webster, M. (2008). New World Dictionary on Line. Retrieved on 10/17/08 http/www. Merriam - Webster .com /.

Yu , F.Y ., Han , C.L.,\& Chan , T.W. (2008) . Experimental Comparisons of Face- to- Face and Anonymous Real -Time Team Competition in a Networked Gaming Learning Environment. Cyber Psychology and Behavior, 11 (4) , 511514 .

Yu , F.y., \& Liu , Y . H. (2009). Creating a Psychologically Safe Online Space for a Student - Generated Questions Learning Activity Via a Different Identity Revelation Modes. British Journal of Educational Technology, 40 (6), 1109-1123.

Yu , F.Y., Chang , L .J., Liu , Y.H., \&Chan , T.W.(2002) . Learning Preferences towards Computerized Competitive Mode. Journal of Computer-Assisted Learning, 18 (3), 341-350.

Zidan, $\mathrm{T}$ (1994). An Exploratory Study of the Acceptability of Target Culture content in EFL Instruction: A Cross-cultural Perspective. Global Age: Issues in English Language Education. Proceedings of the 13th National Symposium of English Language Teaching. CDELT, Ain Shams University. 